\title{
Correction to: Prevalence, Incidence, and Risk Factors for Tinnitus
}

Roshni Biswas and Deborah A. Hall

\section{Correction to:}

Chapter "Epidemiology of Tinnitus" in:

Roshni Biswas and Deborah A. Hall, Curr Topics Behav Neurosci, https://doi.org/10.1007/7854_2020_154

The original version of this chapter unfortunately contained errors in chapter title and keywords.

The incorrect chapter title "Epidemiology of Tinnitus" is now corrected and updated as "Prevalence, Incidence, and Risk Factors for Tinnitus".

The incorrect keywords "Incidence - Measures of effects · Population · Prevalence $\cdot$ Risk factors" are corrected and updated as "Adults $\cdot$ Epidemiology $\cdot$ Measures of effects · Population - Tinnitus". 